\title{
A Framework to Determine the Effectiveness of Maintenance Strategies Lean Thinking Approach
}

\author{
Alireza Irajpour,' Ali Fallahian-Najafabadi,' \\ Mohammad Ali Mahbod, ${ }^{2}$ and Mohammad Karimi ${ }^{3}$ \\ ${ }^{1}$ Faculty of Management and Accounting, Islamic Azad University, Qazvin Branch, Qazvin, Iran \\ ${ }^{2}$ Department of Management, University of Isfahan, Iran \\ ${ }^{3}$ Islamic Azad University, South Tehran Branch, Tehran, Iran
}

Correspondence should be addressed to Ali Fallahian-Najafabadi; alifallahian@yahoo.com

Received 26 March 2014; Accepted 6 June 2014; Published 10 July 2014

Academic Editor: M. Chadli

Copyright (C) 2014 Alireza Irajpour et al. This is an open access article distributed under the Creative Commons Attribution License, which permits unrestricted use, distribution, and reproduction in any medium, provided the original work is properly cited.

\begin{abstract}
The purpose of this paper is to provide a framework that can identify and evaluate the effectiveness of a given maintenance strategy and to rank components of maintenance system. The framework is developed using DEMATEL method on maintenance strategy as a guideline. To gain a richer understanding of the framework, a questionnaire is constructed and answered by experts. Then the DEMATEL method is applied to analyze the importance of criteria and the casual relations among the criteria are constructed. The scope of the paper is limited to performance measurement of maintenance strategies. It is found that the framework is applicable and useful for the strategic management of the maintenance function. It is observed that the influencing and preferred infrastructures for designing Learning and Training are three components, that is, optimal maintenance, CMMS, and RCM which are interdependent on each other and are the fundamental components to realize the designed goals of maintenance process. This paper provides an overview of research and developments in the measurement of maintenance performance. Many tools and techniques have been developed in other fields. However, the applicability of those tools to maintenance function has never been tried. In that respect this topic is novel. It helps in managing maintenance more effectively.
\end{abstract}

\section{Introduction}

Some challenges from modern competitors have provoked many industrial companies to implement new manufacturing approaches $[1,2]$. Particularly salient among these is the concept of lean production $[3,4]$. Lean production is an approach that includes a set of management practices, including just in time, quality systems, work teams, cellular manufacturing, and supplier management, in an integrated system. The main core of lean production is that these practices can work synergistically to create a high quality system for reaching customer demand with no waste.

Some articles on the topic of lean production system emphasize the relationship between implementation of lean and performance. While most of these studies have focused on a single aspect of lean and its performance implications (e.g., [6-8]), a few studies have explored the implementation and performance relationship with two aspects of lean (e.g.,
$[8,9])$. Even fewer studies have investigated the simultaneous synergistic effects of multiple aspects of lean implementation and performance implication. A noteworthy exception is Cua et al.s [10] investigation of implementation of practices related to just in time (JIT), total quality management (TQM), and total preventive maintenance (TPM) programs and their impact on operational performance. However, conceptual research continues to stress the importance of empirically examining the effect of multiple dimensions of lean production programs simultaneously [11].

Companies implement lean strategies to achieve better quality, designing the processes which meet customer requirements and expectations, waste elimination (waste is any activity that does not add value to the product or service) and lead time reduction (it helps a Lean enterprise deliver the products to the customer in a shorter time and reduce total costs, both direct and indirect) [12]. 
Since waste elimination is one of the Lean objectives, it is crucial for companies to identify wastes relevant to defects, waiting time, overproduction (producing more, earlier, or sooner than next workstation demand results in larger inventory and costs), transportation (transportation within Work-In-Process (WIP) resulting from weak plant layout and shortage in understanding of production or process flow), inventory (excess raw materials, finished products, and WIP), unused creativity (failure in exploiting the knowledge and unique abilities of the employees), movement (extra transportation due to wrong location of equipment and tools), and overprocessing (parts of processes that create no added-value to the product or service) $[13,14]$.

Lean principles have been originated from Toyota's production system known as just in time (JIT) production $[15,16]$. The term lean has become widespread after the publication of a book titled The Machine That Changed the World. Then, the term lean production was widely used. Mason-Jones et al. [17] have matched various strategies of supply chain with product type. They have introduced a "leagile" approach which determines the decoupling point between lean and agile paradigms in a supply chain. Sullivan et al. [18] have presented the performance of equipment replacement decision problems within the context of lean manufacturing.

They utilized VSM as a road map for providing necessary information for the analysis of equipment replacement decision problem in lean manufacturing implementation.

Muda and Hendry [19] have proposed a world class manufacturing concept incorporated with lean principles for the make-to-order sector. Pavnaskar et al. [20] have presented a classification scheme for lean manufacturing tools. They have suggested that their classifications scheme enables companies to become lean and serve as a foundation for research into lean concepts. Many researchers have contributed to the definition of lean manufacturing. Shah and Ward [11] have provided a comprehensive definition of lean production which is an integrated sociotechnical system whose objective is to eliminate waste by reducing and minimizing the supplier, customer, and internal variability.

The tools and techniques of lean manufacturing include TQM, TPM, Kanban, Kaizen, SMED, Poka-Yoke, and visual control. Houshmand and Jamshidnezhad [21] have presented an extended model of design process of lean production system by means of process variables. They have used axiomatic design theory for developing hierarchical structure to model a design process of lean production system composed of functional requirements, design parameters, and process variables. Braglia et al. [22] have presented a new approach for a complex production system based on seven iterative steps associated with typical industrial engineering tools including VSM. Shah and Ward [23] have defined the measures of lean production. They have mapped the various conceptual lean strategies [24].

Shin et al. [25] have provided the basic data-driven methods including off-line design and on-line computation algorithms; original idea, basic assumption/condition, and computation complexity were presented. Provided methods were implemented on an industrial benchmark.

1.1. Evolution of Equipment Management. To begin with, there is a requirement to improve an understanding of the basic perception of the maintenance role. Here, it is pertinent to note that the maintenance function has undergone serious change in the last three decades. The traditional perception of maintenance's role is to fix broken items. Taking such a narrow view, maintenance activities have been confined to the reactive tasks of repair actions or item replacement. Thus, this approach is identified as reactive maintenance, breakdown maintenance, or corrective maintenance. A more recent view of maintenance is defined by Gits [26] as "All activities aimed at keeping an item in, or restoring it to, the physical state considered necessary for the fulfilment of its production function." Clearly, the scope of this opinion also contains the proactive tasks such as the following:

$$
\begin{aligned}
& \text { routine servicing and periodic inspection, } \\
& \text { preventive replacement, } \\
& \text { condition monitoring. }
\end{aligned}
$$

In order to maintain equipment, maintenance must carry out some further activities. These activities contain the planning of work, purchasing and control of materials, personnel management, and quality control [27]. This variety of responsibilities and activities convert maintenance from a simple function to a complex function to manage.

Maintenance should ensure equipment availability in order to produce products at the compulsory quantity and quality levels [28]. The scope of maintenance management includes every phase in the life cycle of technical systems (plant, machinery, equipment, and facilities), specification, acquisition, planning, operation, performance evaluation, improvement, and disposal [29].

1.1.1. Breakdown Maintenance (BM). This type of maintenance states the maintenance strategy, after the equipment failure equipment is repaired [30]. This maintenance strategy was mainly implemented in the manufacturing organizations before 1950. In this stage, machines are serviced only when repair is required. This idea has some weaknesses such as the following:
unplanned stoppages,
excessive damage,
spare parts problems,
high repair costs,
excessive waiting and maintenance time,
high trouble shooting problems [31].

1.1.2. Preventive Maintenance $(P M)$. This concept is a type of physical checkup of the equipment to prevent equipment breakdown. Preventive maintenance includes activities which are started after a period of time or amount of machine use [32]. This type of maintenance depends on the estimated 
probability that the equipment will break down in the specified interval. The preventive works are as follows:

equipment lubrication,

cleaning,

parts replacement,

tightening,

adjustment.

1.1.3. Predictive Maintenance (PdM). Predictive maintenance is often mentioned as condition based maintenance (CBM). In this strategy, maintenance is started in response to a specific equipment condition or performance deterioration [33]. The analytic techniques are organized to measure the physical condition of the equipment such as temperature, noise, vibration, lubrication, and corrosion [34]. When one or more of these indicators reach a set deterioration level, maintenance initiatives are assumed to restore the equipment to desired condition. This means that equipment is taken out of service only when direct evidence exists that deterioration has happened. Predictive maintenance is based on the same principle as preventive maintenance. The advantages of predictive maintenance are based on the need to perform maintenance only when the repair is really necessary, not after a specified period of time [32].

1.1.4. Corrective Maintenance (CM). The main core of this concept is to prevent equipment failures. This type of maintenance system has been applied to the improvement of equipment; hence the equipment failure can be removed (improving the reliability) and the equipment can be simply maintained (improving equipment maintainability) [35]. The main difference between corrective and preventive maintenance is based on the time of maintenance action. In the corrective action system a problem must exist before corrective actions are taken [36]. The corrective maintenance is following some purposes such as

$$
\begin{aligned}
& \text { improving equipment reliability, } \\
& \text { maintainability, } \\
& \text { safety, } \\
& \text { reducing design weaknesses (material, shapes), } \\
& \text { reducing deterioration and failures, } \\
& \text { aiming at maintenance-free equipment. }
\end{aligned}
$$

1.1.5. Maintenance Prevention (MP). This type of maintenance system is based on the design phase of equipment. Equipment is designed such that they are maintenance free and an ideal condition of "what the equipment and the line must be" is attained [35]. In the development of new equipment, MP activities must begin at the design stage of equipment [37]. Maintenance prevention often applies some earlier equipment failures and feedback from production areas to ensure equipment design for production systems.
1.1.6. Reliability Centered Maintenance (RCM). RCM can be defined as an organized, rational process for improving the maintenance requirements of a physical resource in its operating context to understand its "inherent reliability," where "inherent reliability" is the level of reliability which can be attained with an effective maintenance program. RCM is a process implemented to determine the maintenance requirements of any machines or equipment in its operating context by recognizing their functions, the causes of failures, and the effects of the failures.

RCM has seven basic steps:

(1) identify the equipment/system to be analyzed;

(2) determine its functions;

(3) determine what constitutes a failure of those functions;

(4) identify the failure modes that cause those functional failures;

(5) identify the impacts or effects of those failures' occurrence;

(6) use RCM logic to select appropriate maintenance tactics;

(7) document your final maintenance program and refine it as you gather operating experience [38].

The various tools employed for affecting maintenance improvement on these 7 steps include

(1) failure mode and effect analysis (FMEA),

(2) failure mode effect and criticality analysis (FMECA),

(3) physical hazard analysis (PHA),

(4) fault tree analysis (FTA),

(5) optimizing maintenance function (OMF),

(6) hazard and operability (HAZOP) analysis.

1.1.7. Productive Maintenance (PrM). The main aim of productive maintenance is to increase the productivity of a manufacturing unit by decreasing the total cost of the equipment over the whole life from design to equipment degradation. The significant features of this maintenance viewpoint are equipment maintainability and reliability focus, as well as cost reduction of maintenance actions. The maintenance strategy including all previous viewpoints to increase equipment productivity by applying preventive maintenance, corrective maintenance, and maintenance prevention is named productive maintenance $[39,40]$ (see Figure 3).

1.1.8. Computerized Maintenance Management Systems (CMMSs). Computerized maintenance management systems (CMMSs) are vigorous for the management of all activities related to the availability, productivity, and maintainability of complex systems. Modern computational facilities have offered a dramatic scope for improved effectiveness and efficiency in, for example, maintenance. Computerized maintenance management systems (CMMSs) have existed, in 


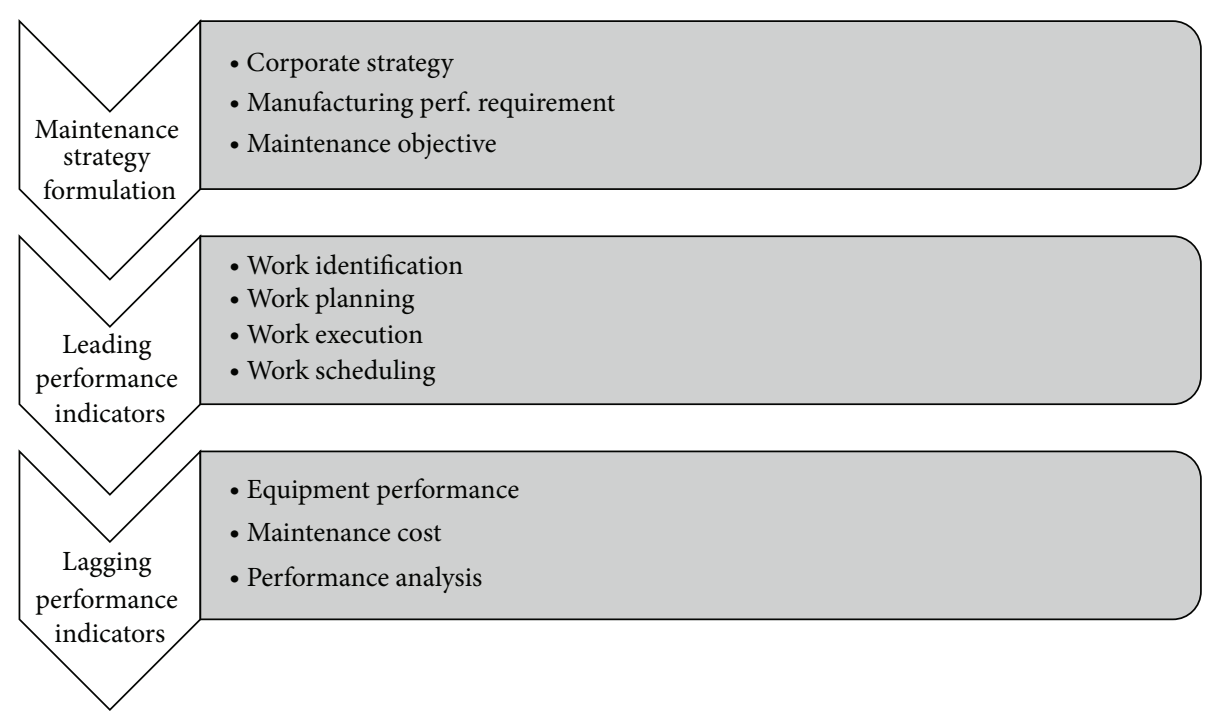

FIGURE 1: The performance measurement framework for the maintenance function.

one form or another, for several decades. CMMS can be used to mechanize the PM function and to help in the control of maintenance inventories and the buying of materials. CMMS can reinforce reporting and analysis capabilities [41, 42]. Accessibility and accuracy of information can provide more reliable decisions in CMMS because of closer working relationships between maintenance and production $[43,44]$.

1.1.9. Total Productive Maintenance (TPM). This methodology is linked to the maintenance systems designed and perfected by “Toyota family" companies including Denso and Aisin Seiki $[45,46]$.

TPM is an innovative approach to maintenance that optimizes equipment effectiveness, removes breakdowns, and promotes autonomous maintenance by operators through day-to-day activities involving total workforce [47]. A strategic approach to improve the performance of maintenance activities is to effectively implement strategic TPM initiatives in the manufacturing organizations. TPM brings maintenance into attention as a necessary part of the business. The TPM initiative is aimed at improving competitiveness of organizations TPM try to find to involve all levels and functions in an organization to optimize the overall effectiveness of production equipment. This method also tunes up existing processes and equipment by reducing mistakes and accidents. TPM is a world class manufacturing (WCM) initiative that pursues to optimize the effectiveness of manufacturing equipment [48].

\subsection{Lean TPM and Maintenance Performance Framework.} The integration of Lean Thinking [3] and total productive manufacturing (Lean TPM) applies the proven business models of "world class" manufacturing enterprise.

The maintenance performance conceptual framework proposed by Muchiri et al. [49] recognizes main processes that lead the maintenance function to delivery of performance required by manufacturing objectives. The conceptual framework supports alignment of maintenance objectives with the manufacturing and corporate objectives. The conceptual framework has three main sections that include maintenance alignment with manufacturing, maintenance effort/process analysis, and maintenance of results performance analysis.

The first area of the conceptual framework pursues aligning the maintenance objectives with the manufacturing strategy. By studying the requirements of the stakeholders, the performance requirements of the manufacturing system can be well-defined. Cognitive mapping is a crucial tool for studying the cause and effect relationship between strategic essentials [50].

1.3. The Maintenance Performance Indicators. The maintenance performance framework summarizes the main essentials that are central in the management of the maintenance function. The essentials make sure that the right work is recognized and effectively implemented for definite results that are in line with the manufacturing performance requirements. Each step is important for effective management of the maintenance function. Both the maintenance process (leading) indicators and maintenance results (lagging) indicators are vital for measuring the performance of the maintenance function. For each essential, the main encounter is to recognize the performance indicators that will express whether the essentials are managed well. Efficient indicators should cover control and monitoring performance and support maintenance actions towards achievement of objectives. Muchiri et al. [49] have provided some indicators that appear often in literature. The classification of Muchiri et al. [49] is applied in this paper for facilitation of performance measurement of maintenance system (see Figure 1). 


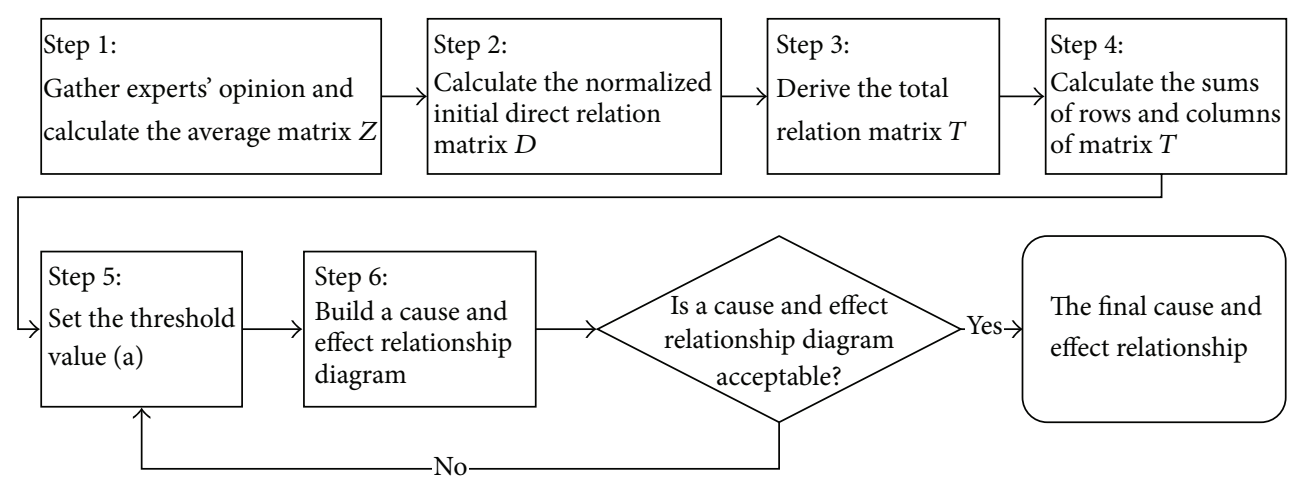

FIgURE 2: The process of the DEMATEL method (adopted from [5]).

1.3.1. Maintenance Process (Leading) Indicators. The maintenance leading indicators monitor some maintenance processes that are as follows:

work identification,

work planning,

work scheduling,

work execution.

Key performance indicators for each process are proposed by Muchiri et al. [49] to measure if requirements of each process are satisfied.

1.3.2. Maintenance Results (Lagging) Indicators. The results of the maintenance process can be divided into efficiency of technical systems and cost systems. The lagging indicators are used to measure maintenance results in terms of equipment performance and maintenance cost [49].

1.4. DEMATEL Method. DEMATEL method was developed between 1972 and 1979 by the Science and Human Affairs Program of the Battelle Memorial Institute of Geneva, with the purpose of studying the complex and intertwined problematic group.

It has been extensively recognized as one of the methods to explain the cause and effect relationship among the criteria [51-55]. This method is applied to analyze the relationship between cause and effects and among evaluation criteria [56] or to originate interrelationship among factors [55].

Based on Shieh et al. [57], the procedure of DEMATEL method is presented in Figure 2.

\section{Research Methodology}

This research includes both classes of fundamental and applied researches because it seeks to explain relations and indices and present model. In this research, survey method is used in terms of time and is descriptive (nonexperimental) research in terms of data collection and classification. Case and field research method is used for presentation of model and technique and final conclusion because the present research includes a series of the methods which aims to describe conditions or relations between the studied phenomena on which basis the technique and model are presented by recognizing the previous position and presenting the present position completely.

The present research is conducted with field and library method such as library references including books, publications, theses, and sources available in the university, scientific centers have been used for theoretical information and review of the literature, and direct observation has been used for collecting data.

2.1. Research Domain (Theme, Space, and Time). Business management and plant management problems particularly problems of maintenance management are some of the multidimensional problems and have abundant complexities which may not be evident at the first look. But it becomes evident after deliberation that these problems have deep and extensive dimensions and their multilateral study may be time consuming. Therefore, it is necessary that each researcher first specify limits of his research to prevent confusion and waste of time and sources.

Thematic domain: in this research, researcher tries to study empowering and effective components of maintenance process optimization in manufacturing industries and presents a suitable and practical model for effective application of each component to achieve goals of organization.

Spatial domain: place of this research includes 9 plants, that is, Pol Film and Atlas Film (production of polymer packaging), Plot and Azin Chap (printing and production of heliogravure print cylinder), Zanjan and Bead Wire Industries in the field of wire and welding electrode production, Fardan Aryan Industries (production of food packs and preform), MEdisk (production of optical compact disc, CD and DVD) and Arya Kian Industries (automobile steering assembly line).

Time domain: time of the present research is year of 2012 in six-month period and information, statistics, and documents relate to this time period.

Requirement of each applied research is study and recognition of factors affecting working field of research. Information collection instrument is questionnaire. Different maintenance strategies and indices and key elements for 
implementation of lean maintenance were identified and these concepts were used in two questionnaires.

In questionnaire 1 , the experts were asked to specify effect of each lean maintenance element as pairwise comparison and announce in front of each row if these components have been applied in their plants and in what level these components are applied for its implementation.

In questionnaire 2, experts were asked to determine effect and significance of each component affecting making maintenance process lean based on four groups of leading indicators and two groups of lagging indicators. This effect is specified according to Saati's scale. It is necessary to note that the following scale is positive for the positive indicators. To determine effect and significance of the component relating to negative indicators, reverse Saati's scale is used.

The indices were determined considering application of interpretive structural modeling approach to ensure theoretical dominance, practical experience, and access due to timeconsuming and different types of the questionnaire compared with the common questionnaires. To ensure comprehensiveness of attitudes, the following indices were obtained:

relationship between working experience of experts and maintenance issue,

the presence of experts as maintenance managers and senior experts,

experts with the related academic education.

Study of the papers which have used interpretive structural method for analyzing results has suggested the number of experts to be between 4 and 64. 64 selected experts include maintenance managers of 9 plants selected for field studies and 5 experienced maintenance experts are working in these plants.

2.2. Data Analysis Method. Extraction of useful results from a research requires application of suitable scientific, accurate, and confirmed methods. In this regard, the following stages are used for analyzing data in this research.

Step 1. It is extraction of approximate agreement matrix for intensity of direct relations between lean maintenance process components adapted from data of questionnaire 6 which was filled by 64 selected experts.

Step 2. This is to structure effect of each lean production component on each other and study feedback and its relations and determine effect of DEMATEL method on lean maintenance process. Application of this method can give the research a suitable structure considering relations between lean maintenance components and make the optimal model policy possible for explaining strategy with lean approach in maintenance process. By extracting two influencing and influenced indices between components of lean maintenance process, effect of components on each other can be evaluated to analyze them properly for ranking these components considering significance of each of them:

making direct relations matrix normal, creating general relations matrix, creating cause and effect matrix,

creating Dependence matrix,

specifying influence order of elements on each other,

extracting influencing and influenced indices of lean production components.

Step 3. Approximate agreement matrix is extracted using data of questionnaire 2 and lean maintenance components are regarded as alternative and maintenance leading and lagging indices are regarded as criterion to which output of Step 2, that is, influencing and influenced indices of components, is added.

Step 4. Determining weight of indices using Shannon entropy method: to determine weight of the index, Shannon entropy method is used instead of experts' view due to uncertainty. In this analysis, it specifies weight and significance of each group of leading and lagging indices and influencing and influenced indices of the process lean production components.

Step 5. Ranking and determining weights of lean maintenance components using TOPSIS technique: TOPSIS technique has been used for ranking and weighting because this technique is a compensatory summative method which compares alternatives through weight of each criterion and normalized numbers on each criterion and calculation of the criterion. It is assumed that TOPSIS has an equal measure for increasing or decreasing values.

Normalization usually requires parameters and criteria which almost have heterogeneous dimensions in multicriteria problems. In compensatory methods, such as TOPSIS, exchange between criteria is compulsory so that weak results of a criterion are neutralized and compensated through good results. Compensatory methods preset more realistic form than noncompensatory methods which ignore the solutions obtained through cuts applied on them:

creating normalized decision matrix, determining positive and negative ideal point, calculating Euclidean distance of positive and negative ideal solutions,

ranking: these numbers are ranked decreasingly to select the preferred option.

Based on output values of TOPSIS, weights of each component are specified using weighted mean method.

Step 6. This step encompasses studying the trend of indices considering implementation levels of lean maintenance components to determine relationship between components of lean maintenances process and trend of maintenances indices in 9 plants selected for field studies, to evaluate effectiveness or loss of efficiency of maintenance process in each one of the plants in six-month period for application or nonapplication of the lean maintenance components. 


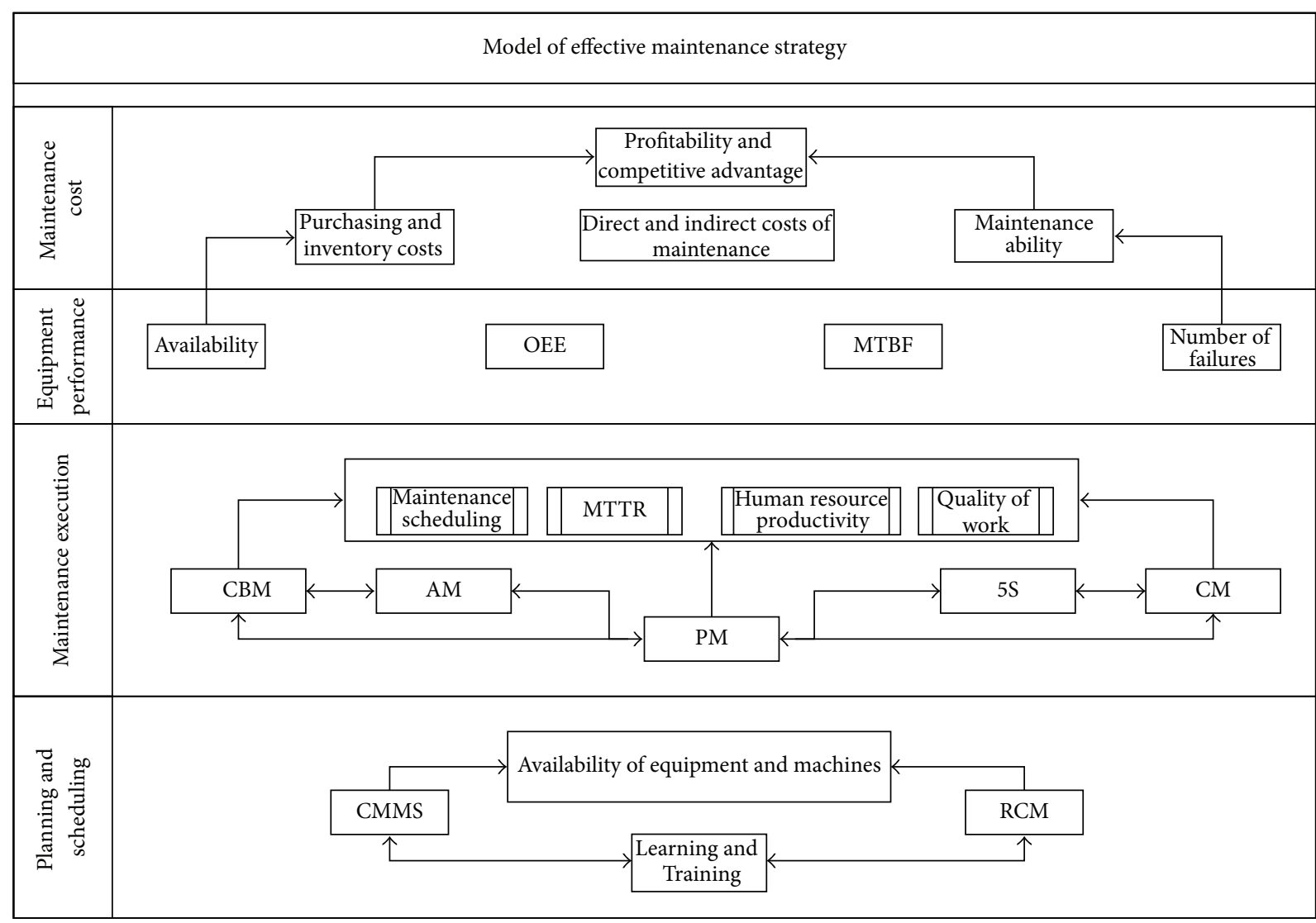

FIgURE 3: Model of effective maintenance strategy.

2.3. Model Integration. There is an integration of outputs of DEMATEL and TOPSIS methods that shows elements dependency and ranks that have been specified. Final results of the conducted field studies and analysis of trend between lean maintenances components and trend of maintenances indices have been achieved. An optimized model is presented for explaining maintenance strategy with lean thinking approach and depicted in Figure 3.

\section{Research Findings and Analysis}

In this way, 9 components have been identified as the factors of which proper implementation can make maintenance process lean and optimal. These components are as follows:

inventory management with lean approach,

$5 \mathrm{~S}$,

CMMS,

training and learning,

CBM,

RCM,

AM,

PM,

CM.
Extraction of approximate agreement matrix for intensity of direct relationship between components of lean maintenance process.

$9 \times 9$ the following pairwise comparison matrix of which components are taken from the studies conducted in review of the literature is a matrix 9 which has been taken from data of questionnaire 6 by 64 selected experts based on group decision making entitled approximate agreement matrix for intensity of direct relationship between components of lean maintenance process. The results have been shown is Table 1.

3.1. Determining Effect of Lean Maintenance Components Using DEMATEL. The following results are obtained by implementing DEMATEL technique as shown in Table 2.

In this step, we specify influence order of elements on each other. Elements of column di indicate hierarchy of the influencing elements and order of elements of column ri indicates hierarchy of the influenced elements. $(d-j)$ indicates position of an element and this position will be certainly influencing in case of positivity $(d-j)$ and will be certainly influenced in case of negativity. $(d+j)$ indicates sum of intensity of an element in terms of influencing element and influenced element. Position of an element will be certainly influencing in case of positivity $(d-j)$ and will be certainly influenced in case of negativity. The above analysis shows that CMMS, RCM, education, and culture building are the most effective on their effective execution in 
TABLE 1: Pairwise matrix of Lean elements of maintenance.

\begin{tabular}{|c|c|c|c|c|c|c|c|c|c|}
\hline $\begin{array}{l}\text { Lean elements of } \\
\text { maintenance }\end{array}$ & $\begin{array}{c}\text { Inventory } \\
\text { management with } \\
\text { lean approach }\end{array}$ & $5 S$ & CMMS & $\begin{array}{c}\text { Training } \\
\text { and } \\
\text { learning }\end{array}$ & $\mathrm{CBM}$ & $\mathrm{RCM}$ & $\mathrm{AM}$ & $\mathrm{PM}$ & $\mathrm{CM}$ \\
\hline $\begin{array}{l}\text { Inventory management } \\
\text { with lean approach }\end{array}$ & 0 & 3 & 1 & 2 & 2 & 2 & 2 & 4 & 4 \\
\hline $5 S$ & 4 & 0 & 3 & 3 & 3 & 2 & 4 & 3 & 3 \\
\hline CMMS & 4 & 3 & 0 & 2 & 4 & 4 & 2 & 4 & 4 \\
\hline Training and learning & 2 & 4 & 2 & 0 & 3 & 3 & 4 & 3 & 4 \\
\hline CBM & 3 & 2 & 3 & 2 & 0 & 4 & 3 & 3 & 4 \\
\hline $\mathrm{RCM}$ & 3 & 2 & 2 & 4 & 4 & 0 & 3 & 4 & 4 \\
\hline $\mathrm{AM}$ & 1 & 2 & 2 & 2 & 3 & 3 & 0 & 4 & 4 \\
\hline PM & 4 & 2 & 3 & 2 & 2 & 2 & 3 & 0 & 4 \\
\hline $\mathrm{CM}$ & 4 & 2 & 2 & 1 & 1 & 2 & 2 & 2 & 0 \\
\hline
\end{tabular}

TABLE 2: Determining effect of Lean maintenance components using DEMATEL.

\begin{tabular}{|c|c|c|c|c|}
\hline & \multicolumn{4}{|c|}{ Influence matrix $\mathrm{T}: 9$ criteria } \\
\hline & Row sum (di) & Column sum (ri) & $\mathrm{di}+\mathrm{ri}$ & $\mathrm{di}-\mathrm{ri}$ \\
\hline Inventory management with lean approach & 4.33 & 5.54 & 9.87 & -1.20 \\
\hline $5 S$ & 5.42 & 4.38 & 9.80 & 1.04 \\
\hline CMMS & 5.82 & 4.03 & 9.85 & 1.79 \\
\hline Training and learning & 5.42 & 3.96 & 9.38 & 1.47 \\
\hline $\mathrm{CBM}$ & 5.22 & 4.68 & 9.90 & 0.54 \\
\hline $\mathrm{RCM}$ & 5.60 & 4.75 & 10.35 & 0.85 \\
\hline $\mathrm{AM}$ & 4.61 & 4.98 & 9.58 & -0.37 \\
\hline $\mathrm{PM}$ & 4.75 & 5.80 & 10.54 & -1.05 \\
\hline $\mathrm{CM}$ & 3.57 & 6.63 & 10.20 & -3.06 \\
\hline
\end{tabular}

TABLE 3: Ranking based on influenced indices of lean production components.

\begin{tabular}{lc}
\hline \multicolumn{2}{c}{$\begin{array}{c}\text { Ranking based on influenced indices of lean production } \\
\text { components }\end{array}$} \\
Component & Column sum (ri) \\
\hline CM & 6.63 \\
PM & 5.80 \\
Inventory management with lean approach & 5.54 \\
AM & 4.98 \\
RCM & 4.75 \\
CBM & 4.68 \\
5S & 4.38 \\
CMMS & 4.03 \\
Training and learning & 3.96 \\
\hline
\end{tabular}

the first level compared with other components. Such analysis specifies that $\mathrm{CM}$ and $\mathrm{PM}$, spare parts store and purchase will be mostly influenced by application and execution of other components. It is necessary to note that these three components are certainly influenced by other components. Outputs of di will be used as influencing positive index and ri will be used as influenced negative index in the next step
TABLE 4: Ranking based on influencing indices of lean production components.

\begin{tabular}{|c|c|}
\hline \multicolumn{2}{|c|}{$\begin{array}{l}\text { Ranking based on influencing indices of lean production } \\
\text { components }\end{array}$} \\
\hline Component & Row sum (di) \\
\hline CMMS & 5.82 \\
\hline $\mathrm{RCM}$ & 5.60 \\
\hline Training and learning & 5.42 \\
\hline $5 \mathrm{~S}$ & 5.42 \\
\hline $\mathrm{CBM}$ & 5.22 \\
\hline PM & 4.75 \\
\hline $\mathrm{AM}$ & 4.61 \\
\hline Inventory management with lean approach & 4.33 \\
\hline $\mathrm{CM}$ & 3.57 \\
\hline
\end{tabular}

for ranking lean maintenance components. The results have been shown in Tables 3 and 4.

3.2. Extraction of Approximate Agreement Matrix for Evaluating Lean Maintenance Components as Maintenance Indices. Approximate agreement matrix is extracted using data of questionnaire 2 and lean maintenance components are regarded as alternative and maintenance leading and lagging 
TABLE 5: Determining weight of indices using Shannon entropy method.

\begin{tabular}{lcc}
\hline Type & Group & Weight \\
\hline & Work identification & $12.32 \%$ \\
Leading indicator & Work planning & $12.40 \%$ \\
& Work scheduling & $13.24 \%$ \\
& Work execution & $20.69 \%$ \\
Lagging indicator & Equipment performance & $13.22 \%$ \\
& Maintenance cost & $28.12 \%$ \\
\hline
\end{tabular}

TABLE 6: Ranking by TOPSIS.

\begin{tabular}{lcc}
\hline \multicolumn{2}{c}{ Ranking by TOPSIS } \\
Lean production components & cli + & $\begin{array}{c}\text { Cumulative } \\
\text { weight }\end{array}$ \\
\hline PM & 0.6422 & $13.8 \%$ \\
CMMS & 0.6286 & $13.5 \%$ \\
RCM & 0.5918 & $12.7 \%$ \\
Inventory management with lean & 0.5325 & $11.5 \%$ \\
approach & 0.4955 & $10.7 \%$ \\
CM & 0.4758 & $10.3 \%$ \\
Training and learning & 0.4479 & $9.6 \%$ \\
CBM & 0.4172 & $9.0 \%$ \\
5S & 0.4104 & $8.8 \%$ \\
AM &
\end{tabular}

indices are regarded as criterion to which output of Step 2, that is, influenced and influencing indices of components, is added. The indices which are included in dark cells are regarded as positive indices and the indices which are in bright cells are regarded as negative indices.

\subsection{Determining Weight of Indices Using Shannon Entropy} Method. Considering the extracted weights, it is observed that weight of each main class of the maintenance leading and lagging indices is shown in Table 5.

Considering the analysis in Table 6 , we see that 4 components, that is, PM, CMMS, RCM, and spare parts purchase and store, with lean thinking approach are the most important components for moving toward optimum in maintenance. These four components include $52 \%$ of the lean weight of the maintenance process.

\section{Model Presentation}

Outputs of integration methods have been applied in selecting optimal maintenance strategy, optimal model is presented for explaining maintenance with lean thinking approach.

In this model which was presented as bottom-up method, it is observed that the influencing and preferred infrastructures for designing Learning and Training are three components, that is, optimal maintenance, CMMS, and RCM which are interdependent on each other and are the fundamental components to realize the designed goals of maintenance process. In the next step, other components of lean maintenance are given to realize other goals.

\section{Conclusion}

The presented model is an applied model which can be used in different plants and different production lines for optimizing maintenance process. In the performed analyses, it was observed that each one of the lean maintenance components should be valued differently; significance and weight of each of them should be included properly in budgeting for execution. To execute these components for realizing maintenance goals, one should start with the mentioned infrastructures and then apply other components.

In the further researches based on the methodology introduced in the research, one can replace ANP (analytical network process) with TOPSIS or utilize combinatory statistical analysis of Fisher's test and logistic regression test instead of multicriteria decision methods and compare their results with the present research.

\section{Conflict of Interests}

The authors declare that there is no conflict of interests regarding the publication of this paper.

\section{References}

[1] R. W. Hall, Attaining Manufacturing Excellence: Just-in-Time, Total Quality, Total People Involvement, Dow Jones-Irwin, Homewood, Ill, USA, 1987.

[2] J. R. Meredith and R. McTavish, "Organized manufacturing for superior market performance," Long Range Planning, vol. 25, no. 6, pp. 63-71, 1992.

[3] J. P. Womack and D. T. Jones, Lean Thinking: Banish Waste and Create Wealth in Your Corporation, Simon \& Schuster, New York, NY, USA, 1996.

[4] J. P. Womack, D. T. Jones, and D. Roos, The Machine That Changed the World, Harper Perennial, New York, NY, USA, 1990.

[5] D. Sumrit and P. Anuntavoranich, "Using DEMATEL method to analyze the causal relations on technological innovation capability evaluation factors in Thai technology-based firms," International Transaction Journal of Engineering, Management, \& Applied Sciences \& Technologies, vol. 4, no. 2, 2012.

[6] J. R. Hackman and R. Wageman, "Total quality management: empirical, conceptual, and practical issues," Administrative Science Quarterly, vol. 40, no. 2, pp. 309-342, 1995.

[7] D. Samson and M. Terziovski, "Relationship between total quality management practices and operational performance," Journal of Operations Management, vol. 17, no. 4, pp. 393-409, 1999.

[8] K. E. McKone, R. G. Schroeder, and K. O. Cua, "Impact of total productive maintenance practices on manufacturing performance," Journal of Operations Management, vol. 19, no. 1, pp. 39-58, 2001.

[9] B. B. Flynn, S. Sakakibara, and R. G. Schroeder, "Relationship between JIT and TQM: practices and performance," Academy of Management Journal, vol. 38, no. 5, pp. 1325-1360, 1995. 
[10] K. O. Cua, K. E. McKone, and R. G. Schroeder, "Relationships between implementation of TQM, JIT, and TPM and manufacturing performance," Journal of Operations Management, vol. 19, no. 6, pp. 675-694, 2001.

[11] R. Shah and P. T. Ward, "Lean manufacturing: context, practice bundles, and performance," Journal of Operations Management, vol. 21, no. 2, pp. 129-149, 2003.

[12] S. Bhasin and P. Burcher, "Lean viewed as a philosophy," Journal of Manufacturing Technology Management, vol. 17, no. 1, pp. 5672, 2006.

[13] J. Drew, B. McCallum, and S. Roggenhofer, Journey to Lean; Making Operational Change Stick, Palgrave Macmillan, New York, NY, USA, 2004.

[14] M. Arashpour, M. R. Enaghani, and R. Andersson, "The rationale of lean and TPM," in Proceedings of the International Conference of Engineering and Operations Management (IEOM '10), Dhaka, Bangladesh, 2010.

[15] Z. Tang, R. Chen, and J. I. Xuehong, "An innovation process model for identifying manufacturing paradigms," International Journal of Production Research, vol. 43, no. 13, pp. 2725-2742, 2005.

[16] F. K. Pil and T. Fujimoto, "Lean and reflective production: the dynamic nature of production models," International Journal of Production Research, vol. 45, no. 16, pp. 3741-3761, 2007.

[17] R. Mason-Jones, B. Naylor, and D. R. Towill, "Lean, agile or league? Matching your supply chain to the marketplace," International Journal of Production Research, vol. 38, no. 17, pp. 4061-4070, 2000.

[18] W. G. Sullivan, T. N. McDonald, and E. M. Van Aken, "Equipment replacement decisions and lean manufacturing," Robotics and Computer-Integrated Manufacturing, vol. 18, no. 3-4, pp. 255-265, 2002.

[19] S. Muda and L. Hendry, "Proposing a world-class manufacturing concept for the make-to-order sector," International Journal of Production Research, vol. 40, no. 2, pp. 353-373, 2002.

[20] S. J. Pavnaskar, J. K. Gershenson, and A. B. Jambekar, "Classification scheme for lean manufacturing tools," International Journal of Production Research, vol. 41, no. 13, pp. 3075-3090, 2003.

[21] M. Houshmand and B. Jamshidnezhad, "An extended model of design process of lean production systems by means of process variables," Robotics and Computer: Integrated Manufacturing, vol. 22, no. 1, pp. 1-16, 2006.

[22] M. Braglia, G. Carmignani, and F. Zammori, "A new value stream mapping approach for complex production systems," International Journal of Production Research, vol. 44, no. 18-19, pp. 3929-3952, 2006.

[23] R. Shah and P. Ward, "Defining and developing measures of lean production," Journal of Operations Management, vol. 25, no. 4, pp. 785-805, 2007.

[24] S. Vinodh and S. K. Chintha, "Leanness assessment using multigrade fuzzy approach," International Journal of Production Research, vol. 49, no. 2, pp. 431-445, 2011.

[25] Y. Shin, S. X. Ding, A. Haghani, H. Hao, and P. Zhang, "A comparison study of basic data-driven fault diagnosis and process monitoring methods on the benchmark Tennessee Eastman process," Journal of Process Control, vol. 22, no. 9, pp. 1567-1581, 2012.

[26] C. W. Gits, "Design of maintenance concepts," International Journal of Production Economics, vol. 24, no. 3, pp. 217-226, 1992.
[27] V. Priel, Systematic Maintenance Organization, McDonald and Evan, London, UK, 1974.

[28] L. M. Pintelon and L. F. Gelders, "Maintenance management decision making," European Journal of Operational Research, vol. 58, no. 3, pp. 301-317, 1992.

[29] M. Murray, K. Fletcher, J. Kennedy, P. Kohler, J. Chambers, and T. Ledwidge, "Capability assurance: a generic model of maintenance," in Proceedings of the 2nd International Conference of Maintenance Societies, pp. 1-5, Melbourne, Australia, 1996.

[30] T. Wireman, World Class Maintenance Management, Industrial Press, New York, NY, USA, 1990.

[31] A. D. Telang, "Preventive maintenance," in Proceedings of the National Conference on Maintenance and Condition Monitoring, K. Vijayakumar, Ed., pp. 160-73, Government Engineering College, Institution of Engineers, Cochin Local Centre, Thissur, India, Febuary 1998.

[32] F. Herbaty, Handbook of Maintenance Management: Cost Effective Practices, Noyes Publications, Park Ridge, NJ, USA, 2nd edition, 1990.

[33] D. Vanzile and I. Otis, "Measuring and controlling machine performance," in Handbook of Industrial Engineering, G. Salvendy, Ed., John Wiley \& Sons, New York, NY, USA, 1992.

[34] R. Brook, "Total predictive maintenance cuts plant costs," Plant Engineering, vol. 52, no. 4, pp. 93-95, 1998.

[35] H. R. Steinbacher and N. L. Steinbacher, TPM for America, Productivity Press, Portland, Ore, USA, 1993.

[36] L. R. Higgins, D. P. Brautigam, and R. K. Mobley, Maintenance Engineering Handbook, McGraw-Hill, New York, NY, USA, 5th edition, 1995.

[37] K. Shirose, TPM for Operators, Productivity Press, Portland, Ore, USA, 1992.

[38] J. D. Campbell, The Reliability Handbook, Clifford-Elliott, Ontario, Canada, 1999.

[39] Y. Wakaru, TPM for Every Operator, Productivity Press, Portland, Ore, USA, 1988.

[40] B. Bhadury, Total Productive Maintenance, Allied Publishers, New Delhi, India, 1988.

[41] R. Hannan and D. Keyport, "Automating a maintenance work control system," Plant Engineering, vol. 45, no. 6, pp. 108-110, 1991.

[42] T. Singer, "Are you using all the features of your CMMS? Following this even-step plan can help uncover new benefits," Plant Engineering, vol. 53, no. 1, p. 32, 1999.

[43] R. Dunn and D. Johnson, "Getting started in computerized maintenance management," Plant Engineering, vol. 45, no. 7, pp. 55-58, 1991.

[44] A. Labib, "Computerised maintenance management systems," in Complex System Maintenance Handbook, pp. 417-435, Springer, London, UK, 2008.

[45] S. Nakajima, Introduction to Total Productive Maintenance (TPM), Productivity Press, Portland, Ore, USA, 1988.

[46] D. McCarthy and N. Rich, Lean TPM: A Blueprint for Change, Butterworth-Heinemann, 2004.

[47] B. Bhadury, "Management of productivity through TPM," Productivity, vol. 41, no. 2, pp. 240-251, 2000.

[48] K. Shirose, TPM Team Guide, Productivity Press, Portland, Ore, USA, 1995.

[49] P. Muchiri, L. Pintelon, L. Gelders, and H. Martin, "Development of maintenance function performance measurement framework and indicators," International Journal of Production Economics, vol. 131, no. 1, pp. 295-302, 2011. 
[50] F. Ackermann, C. Eden, and I. Brown, The Practice of Making Strategy: A Step by Step Guide, SagePublication, London, UK, 2005.

[51] Y. J. Chiu, H. C. Chen, G. H. Tzeng, and J. Z. Shyu, "Marketing strategy based on customer behaviour for the LCD-TV," International Journal of Management and Decision Making, vol. 7, no. 2-3, pp. 143-165, 2006.

[52] J. J. H. Liou, G. Tzeng, and H. Chang, "Airline safety measurement using a hybrid model," Journal of Air Transport Management, vol. 13, no. 4, pp. 243-249, 2007.

[53] G. H. Tzeng, C. H. Chiang, and C. W. Li, "Evaluating intertwined effects in e-learning programs: a novel hybrid MCDM model based on factor analysis and DEMATEL," Expert Systems with Applications, vol. 32, no. 4, pp. 1028-1044, 2007.

[54] W. W. Wu and Y. T. Lee, "Developing global managers' competencies using the fuzzy DEMATEL method," Expert Systems with Applications, vol. 32, no. 2, pp. 499-507, 2007.

[55] C. Lin and G. Tzeng, "A value-created system of science (technology) park by using DEMATEL," Expert Systems with Applications, vol. 36, no. 6, pp. 9683-9697, 2009.

[56] Y. P. Yang, H. M. Shieh, J. D. Leu, and G. H. Tzeng, "A novel hybrid MCDM model combined with DEMATEL and ANP with applications," International Journal Operational Research, vol. 5, no. 3, pp. 160-168.

[57] J. I. Shieh, H. H. Wu, and K. K. Huang, "A DEMATEL method in identifying key success factors of hospital service quality," Knowledge-Based Systems, vol. 23, no. 3, pp. 277-282, 2010. 


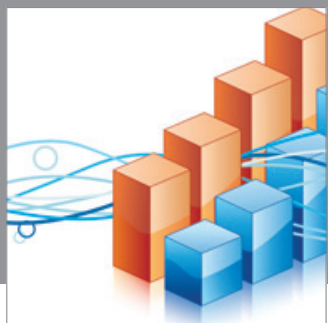

Advances in

Operations Research

mansans

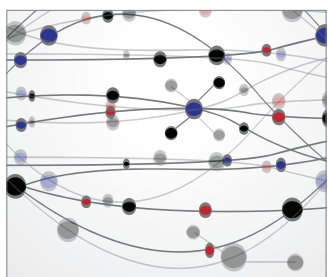

The Scientific World Journal
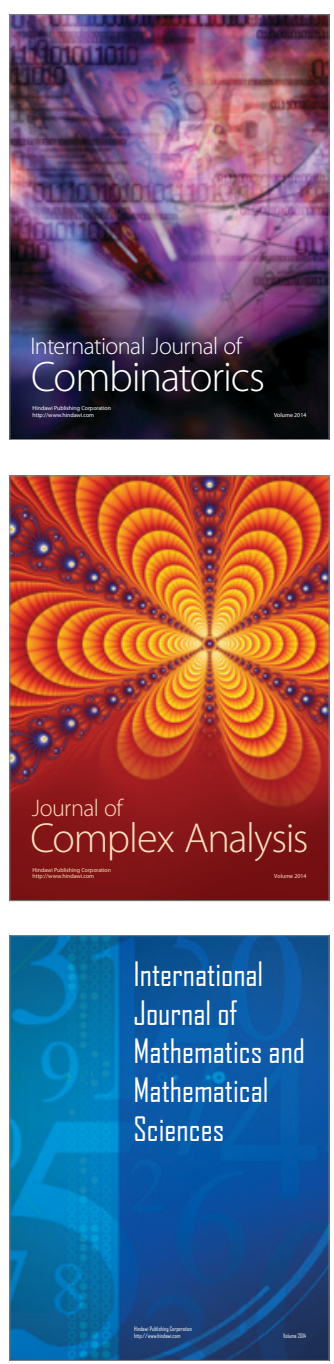
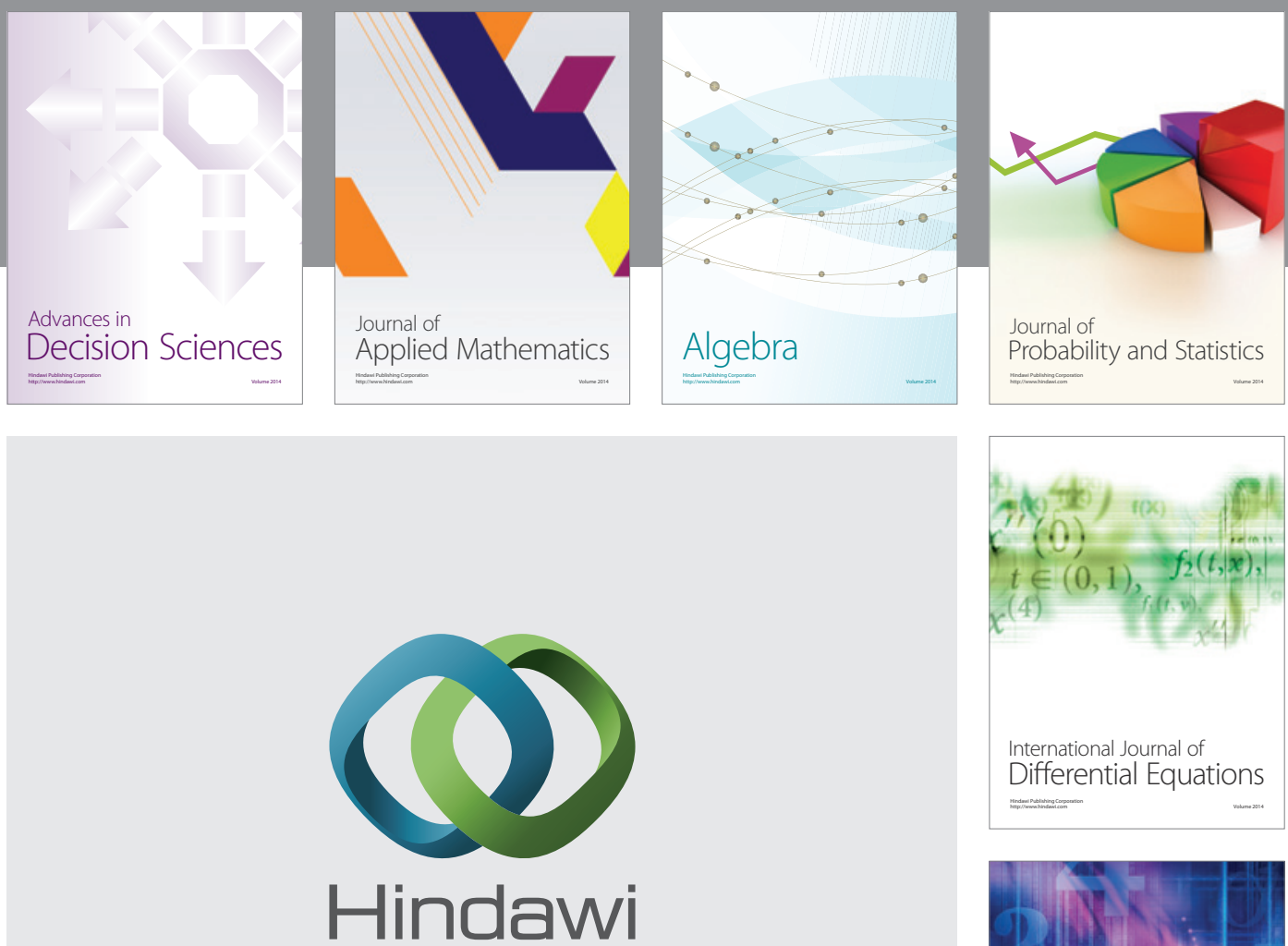

Submit your manuscripts at http://www.hindawi.com
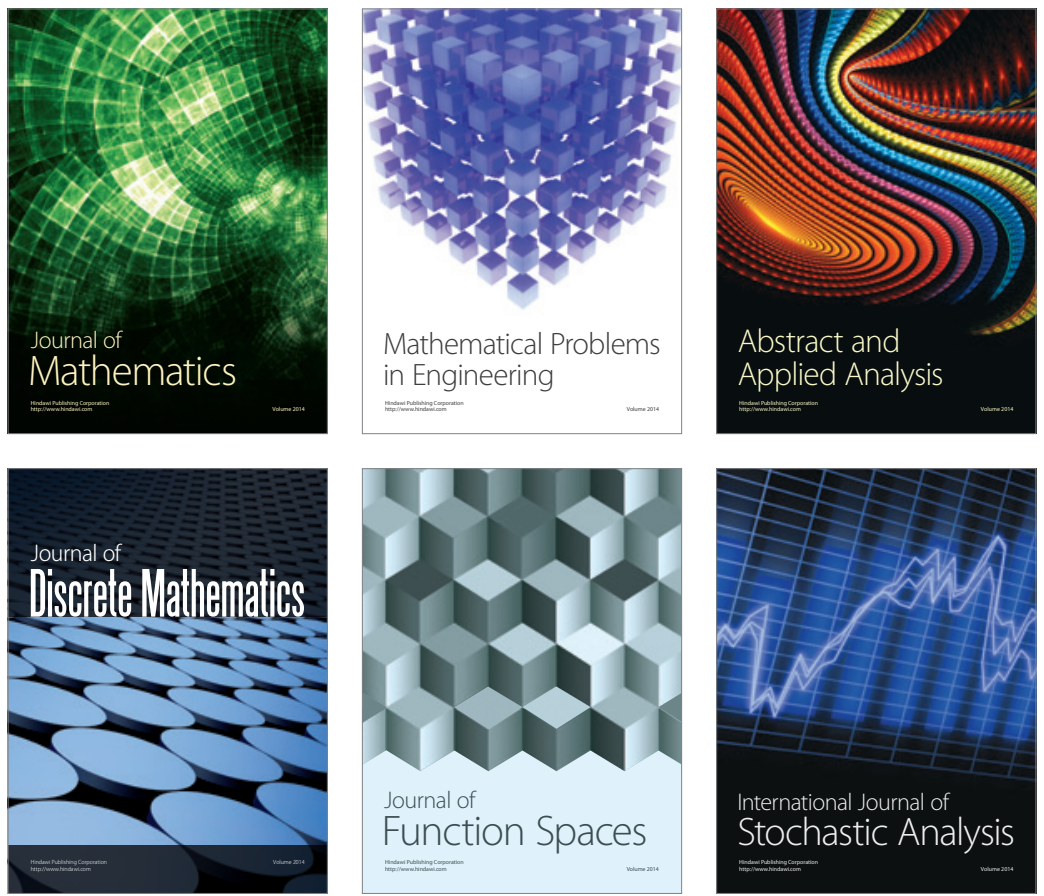

Journal of

Function Spaces

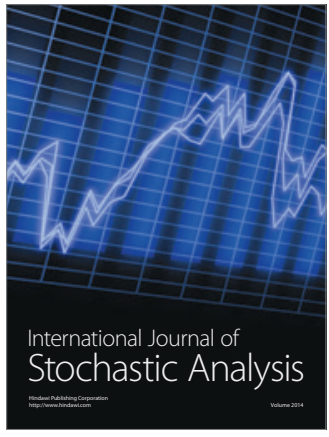

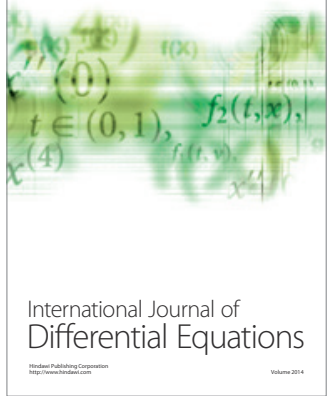
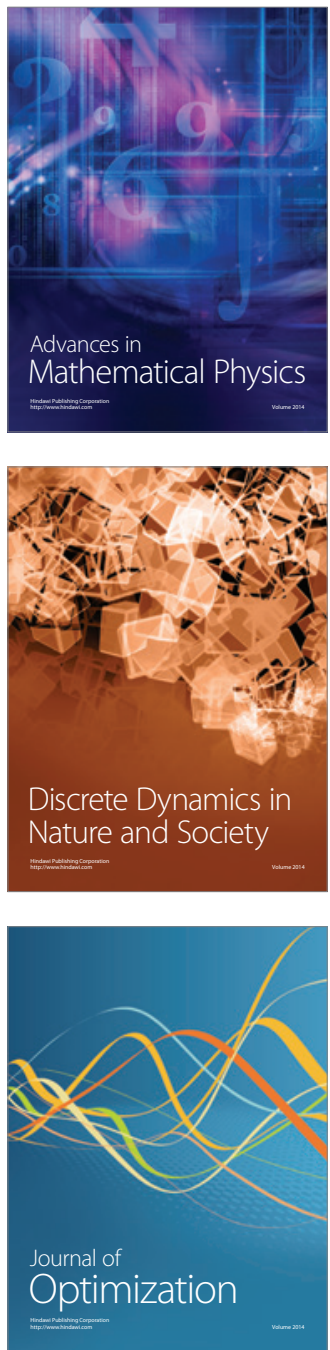